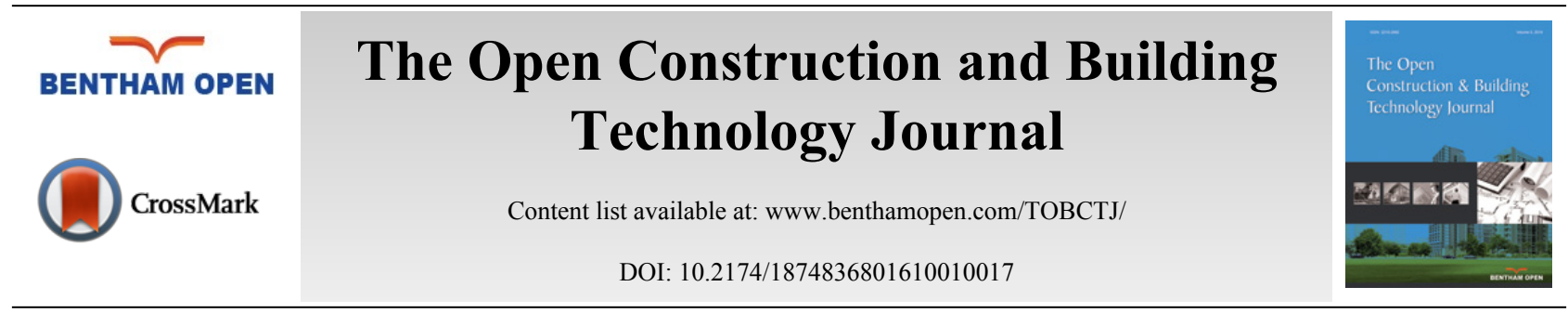

\title{
Design of Automatic Positioning Equipment for Cross Beam
}

\author{
Hong Zhang ${ }^{*}$, Zili Luo and Jin Guo \\ CCCC Second Harbor Engineering Co., Ltd., Wuhan 430022, China
}

\begin{abstract}
By analyzing and summarizing the process and requirements of cross beam installation, an underwater three-direction positioning equipment is developed. Through three sets of hydraulic cylinders and MGE sliders combining hydraulic synchronizing lifting technique and computer communication technology, precise automatic positioning is achieved. The equipment can be used in positioning other similar large structures.
\end{abstract}

Keywords: CAN-bus, cross beam positioning, hydraulic synchronizing lifting, MGE sliders.

\section{INTRODUCTION}

The water slide used for large ships' sailing and launching is fixed in the precast reinforced concreted cross beams after matching in the onshore, installed with the cross beams to the completed base. After the installation is completed, the location of the water slide will be well fixed. Ships carrying ship girder sail in the water along the slideway. In order to ensure the ship girder smoothly into the water, higher requirements on the installation precision of slideway is put forward, and the installation accuracy depends on cross beams installation accuracy. We must ensure that installation precision of cross beams, and cross beams should be adjusted accordingly during construction.

In the current engineering practice, cross beams are usually adjusted by following methods [1 - 3].

1. Spacer needs to be installed on the cross beam to be installed. Observing actinomycetes plumb bob and beam frame scale deviation, the diver determines the deviation of location of the cross beam and informs the boar crane operator. The operator adjusts the location of cross beams. Tenon and wedge are poured in front and back of cross beams, and finally the tenon of cross beams and wedge of those are well matched to ensure the precision of cross beams' installation.

2. Around the cross beam underwater pile cap to be installed, the temporary steel trellis columns, precast platform and cross beam lifting frame are constructed. After on spotting pouring cross beams, they are put down through multiple hoists synchronizingly. According to the deviation informed by divers, hoists are adjusted to ensure the location deviation of cross beams falls within the scope of the accuracy requirement.

3. Steel casing is immersed at the predetermined position of the pile cap. Steel casing is used to form a local cofferdam. The underwater pile caps are poured on the dry construction site, while the guide rods are embedded in the pouring pile cap. The guide mechanism is installed in the cross beam. The installation position is ensured by the guide rod and guiding mechanism during being lifted. The installation accuracy is guaranteed by the location of pile caps and rod position.

The methods above can ensure the installation accuracy of cross beams within $\pm 4 \mathrm{~mm}[2]$. However, these methods require the installation or construction of extra auxiliary structures, while the auxiliary structures and cross beams are not independent from the secondary structures. Therefore, these are applied to individual construction program. Meanwhile, the traditional methods are affected by river flow, flow velocity and other underwater natural conditions.

\footnotetext{
* Address correspondence to this author at the CCCC Second Harbor Engineering Co., Ltd., Wuhan 430022, China; Tel: 86-27-83920777; Fax: 86-27-83920888; E-mail: zgb@sneb.com.cn
} 
The progress of installation and accuracy is difficult to achieve. And traditional construction methods can not meet the construction requirements [4], a system of automation and digital modulation [5, 6] without staffs' underwater operation is needed to be developed.

The Wuhan's slipway project is located in the north shore of mid Yangtze River. The average sediment concentration of the channel area is annual $0.61 \mathrm{~kg} / \mathrm{m}^{3}$ and the water quality is low mineralization freshwater with heavy calcium carbonation. Cross beams are of great amount and the maximum water depth reaches to almost $30 \mathrm{~m}$. While the rail head surface elevation and side access dislocation differential requirements is less than $1 \mathrm{~mm}$, two track gauge error is in $\pm 5 \mathrm{~mm}$, and axis orbit error is less than $5 \mathrm{~mm}$. Conventional methods cannot complete this project efficiently. Through the theoretical analysis of location adjustment of cross beams, introducing a three position adjusting device, combined with hydraulic synchronous lifting technology and computer networking technology, a high accuracy can be achieved as well as high efficiency, automatic and digital adjustment process, which can be applied to other similar large beam adjusting engineering project.

\section{CROSS BEAM LOCATION ADJUSTMENT ANALYSIS}

In the actual construction, concreted piles are in the direction of the center of arrangement in depth of the river along the banks. The cross beams with fixed track above are hanged by hanging bracket to the concreted piles poured in advance. Adjusting device is fixed on the hanger and is with the hanger in to the river with one end falling in the pile the other end supported on the top beam section. The link between head and end of installed and to be installed beams can be realized by adjusting the beam section to be installed. The structure of using tri-direction-jack to adjust cross beam is shown in Fig. (1).

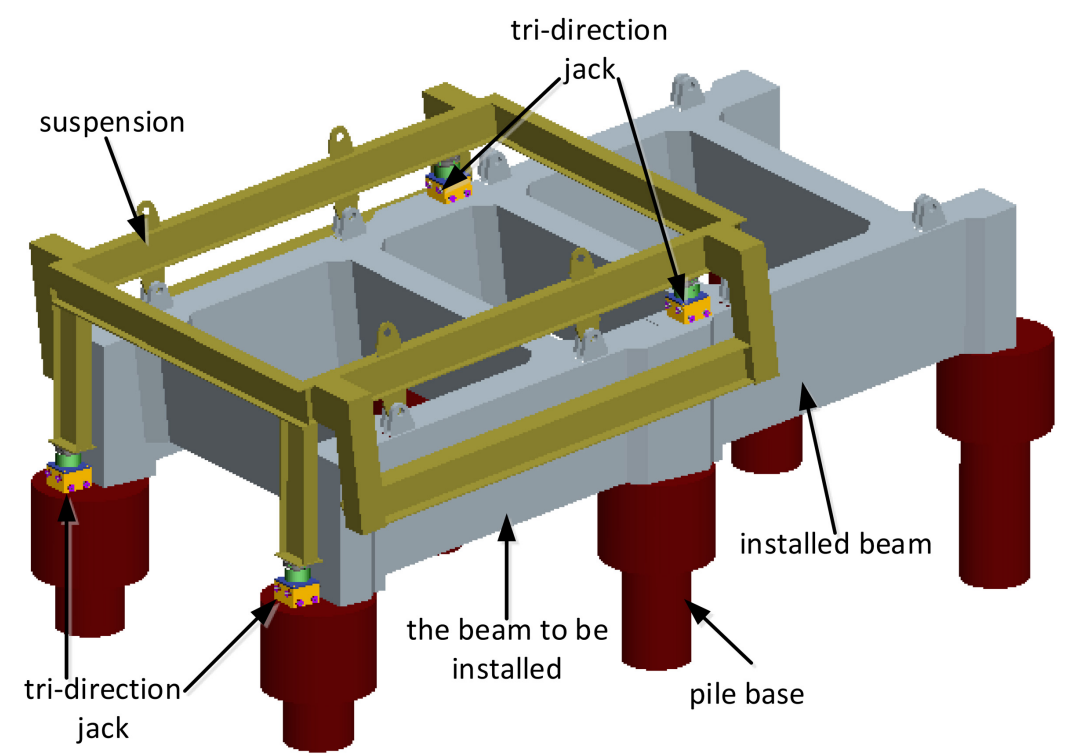

Fig. (1). Structure of cross beam positioning scheme.

Four series of tri-direction-jack are linked to the bottom of the four pillars of the hanger. The whole structure is lifted to the pre determined location. The bottom of four series of three direction lifting jack is linked to preset concrete piles. After finishing the lift, according to the difference in displacement and angle between the current position of cross beams and determined position, pumping drives four series of tri-direction-jacks to synchronize precise adjustment.

During the adjustment, the possible movement of the cross beams could be: lifting, traversing, advancing and retreating, side rolling, pitching and fixed rotation, as shown in Fig. (2).

Among, lifting, traversing, advancing and retreating, side rolling and pitching belong to translation location adjustment, which are realized by controlling the corresponding cylinder (only one direction of action is required among horizontal lateral, longitudinal lateral and vertical cylinder); meanwhile, the fixed rotation is defective location adjustment, and it should be controlled by synchronized movement of tri-direction-jack longitudinal and horizontal transverse cylinders. The horizontal displacement is created by the combined movement of horizontal longitudinal and 
horizontal transverse at the linking point of lift jack and hanger. The synchronized motion of four sets of tri-directionjack creates the horizontal rotation of cross beams.

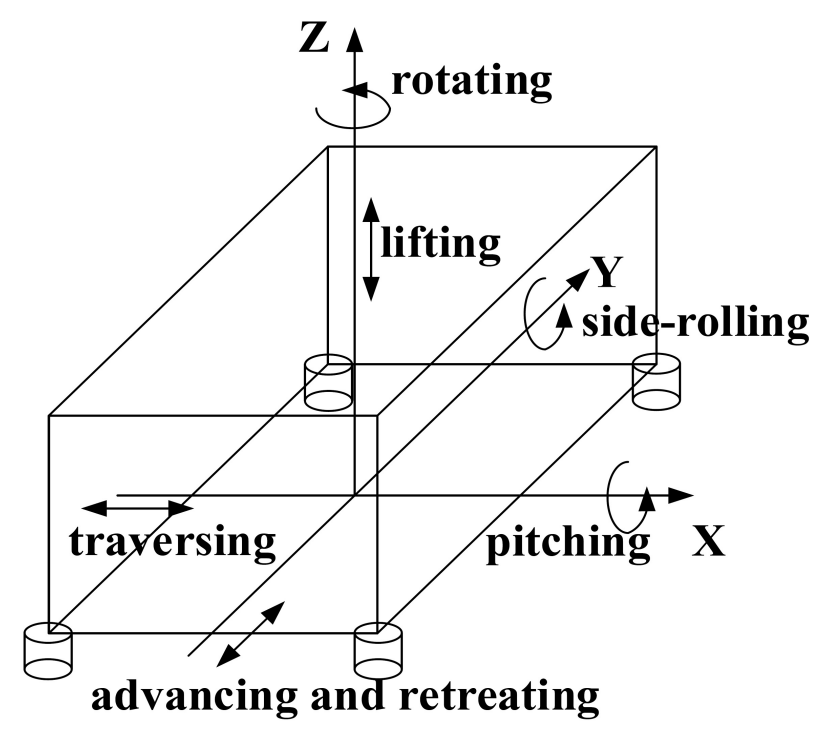

Fig. (2). Movement mode of cross beam.

\section{DESIGN OF AUTOMATIC ADJUSTING SYSTEM AND EQUIPMENT}

\subsection{System Design}

The displacement adjustment of cross beams consists of the tri-direction-jack, hydraulic pumpstation, computercontrol system and accessories, as shown in Fig. (3).

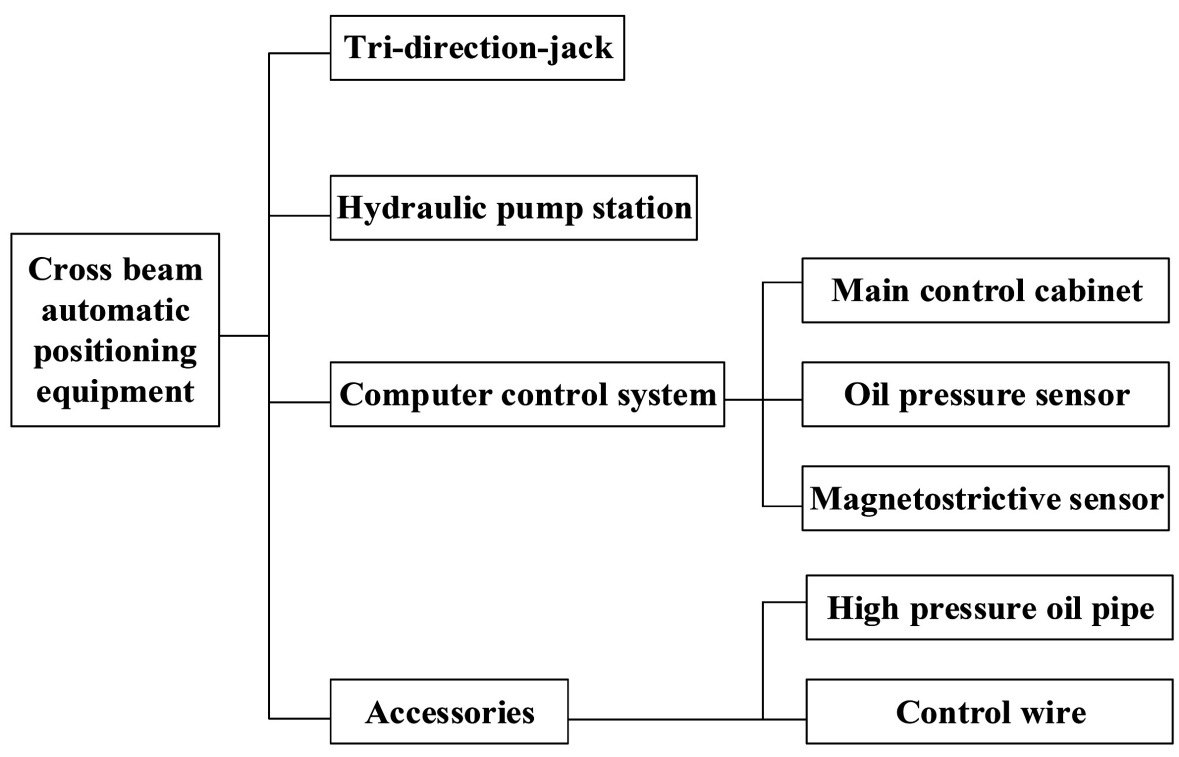

Fig. (3). Composition of cross beam automatic positioning equipment.

The automatic adjusting system equipment is performed by tri-direction-jack, that is layered at the four legs of the cross beam hanger. An independent tri-direction-jack can adjust the point within the three dimension space of $200 \mathrm{~mm} \times 200 \mathrm{~mm} \times 200 \mathrm{~mm}$. The four three-direction lift jacks can complete the six degree freedom of the cross beams. Hydraulic pump improves force to tri-direction-jack, with each hydraulic pump to drive two tri-direction-jack. The 
primary controller is installed at the hydraulic bump, outputting the pump flow and overflow pressure through integrated control pumps. The communication between controllers is realized via CAN bus, ensuring the synchronization of each group of three direction pumps. Oil pressure and magnetostrictive sensor are installed in the cylinder valve block and cylinder of tri-direction-jack. The sensor transmits messages of real time conditions of cylinder to the control system via CAN bus, creating closed loop control system and ensuring rapid, stable and accurate displacement adjustment.

In the construction, tri-direction-jack is layered as shown in Figs. $\mathbf{( 4 , 5 ) .}$

\subsection{Design of Tri-direction-jack}

Tri-direction-jack is composed of three sets of orthogonally positioned cylinders, which provide thrust or pull. Each direction of the jack creates a unidirectional displacement of corresponding structure in a certain direction. Three cylinders' synchronized movement will be able to get arbitrary displacement in three dimensions, resulting in a threedimension displacement at the linked point of tri-direction-jack and the adjusted structure. Using three or more threedirection jacks for displacement adjustment synchronization, a displacement adjustment of six freedom of the structure can be realized. The structure of three dimension jack is shown in Fig. (6).

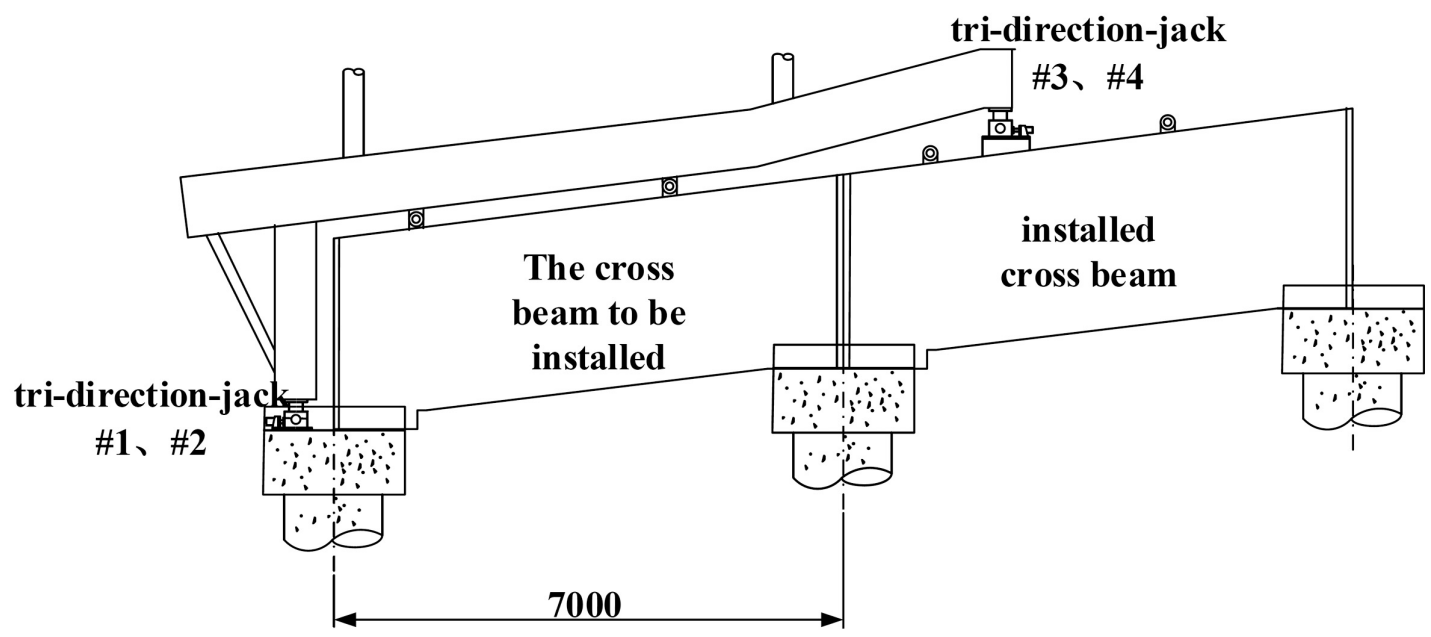

Fig. (4). Elevation drawing of tri-direction-jack's position.

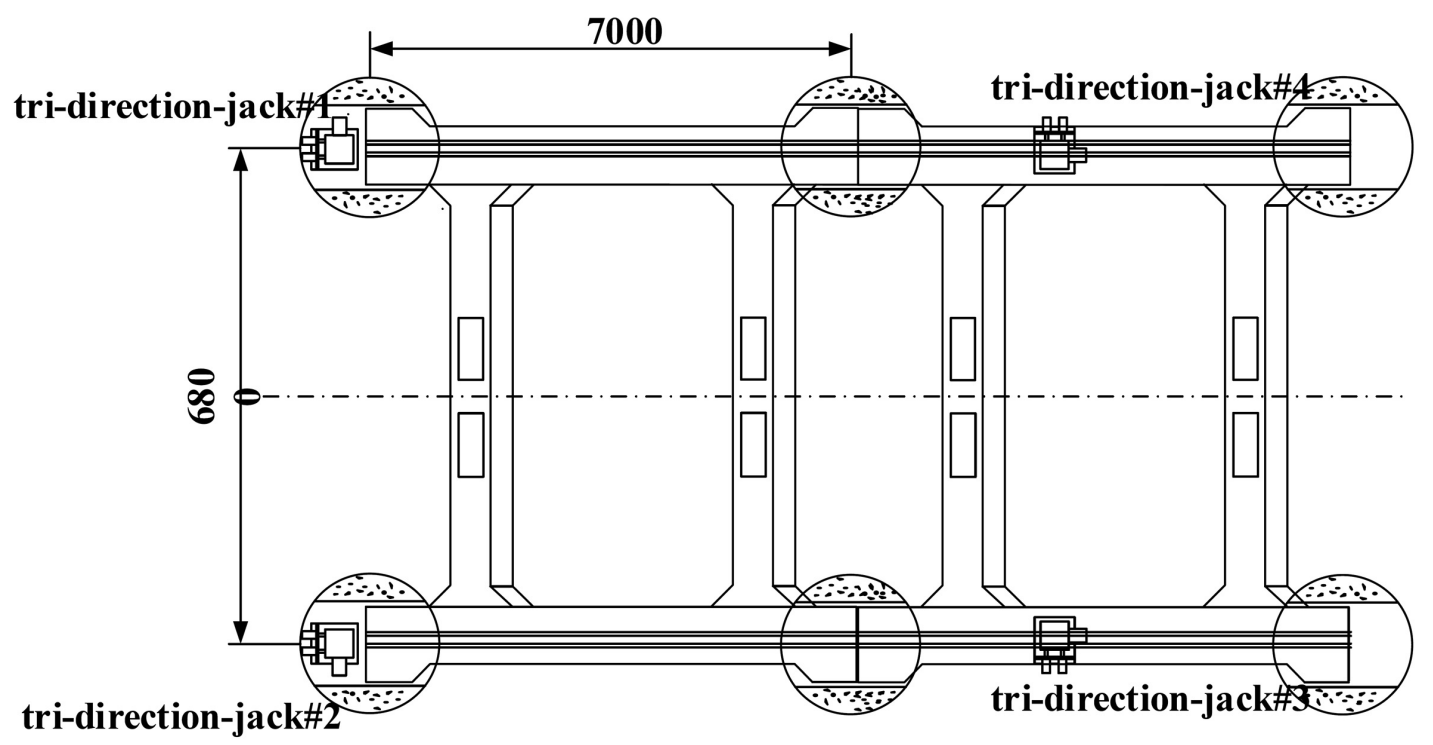

Fig. (5). Planar graph of tri-direction-jack's position. 


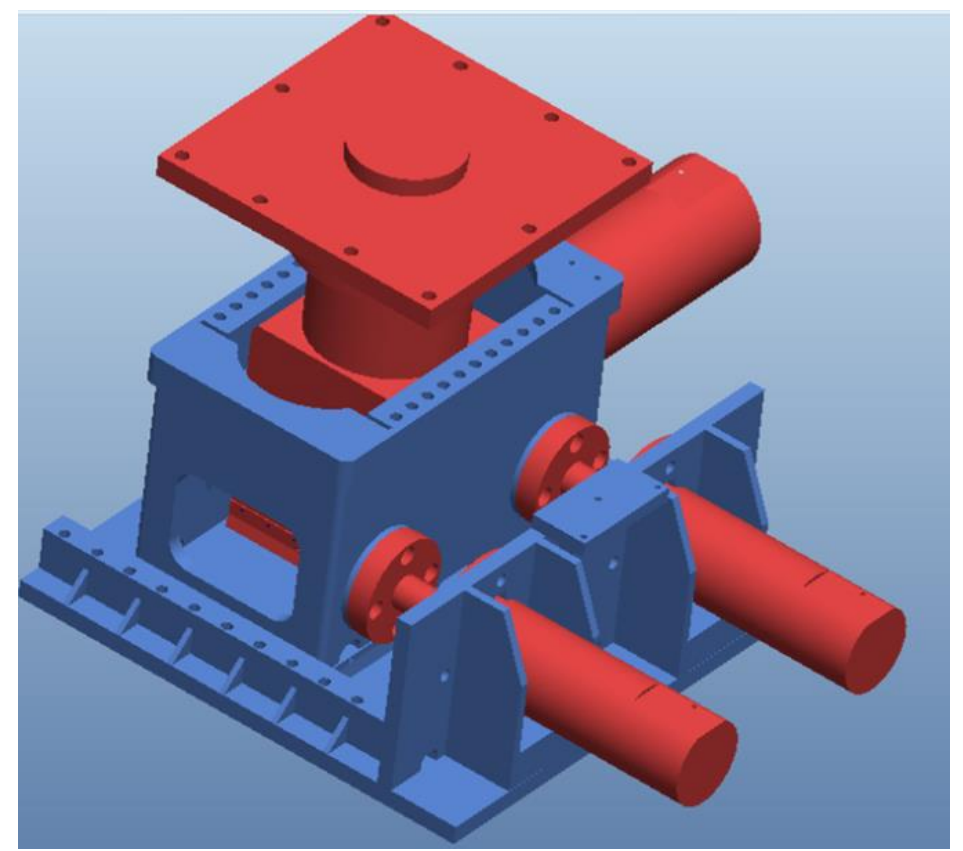

Fig. (6). Structure of tri-direction jack.

To guarantee three degree freedom displacement adjustment of the object, three dimension jack applies three jack hydraulic cylinder to be the top three drivers, two of which are horizontal orthogonal hydraulic cylinders corresponding to two pairs translineing, to enable the object to move at all directions on the horizon. A set of vertically disposed cylinders is adjusted to complete the displacement of the object in the vertical direction. Meanwhile, the longitudinal of the cylinder is linked with adjusted equipment by ball joint. This enables three direction jack to adapt to deflection of the adjusted object within a certain range. Its structure is shown in Fig. (7).
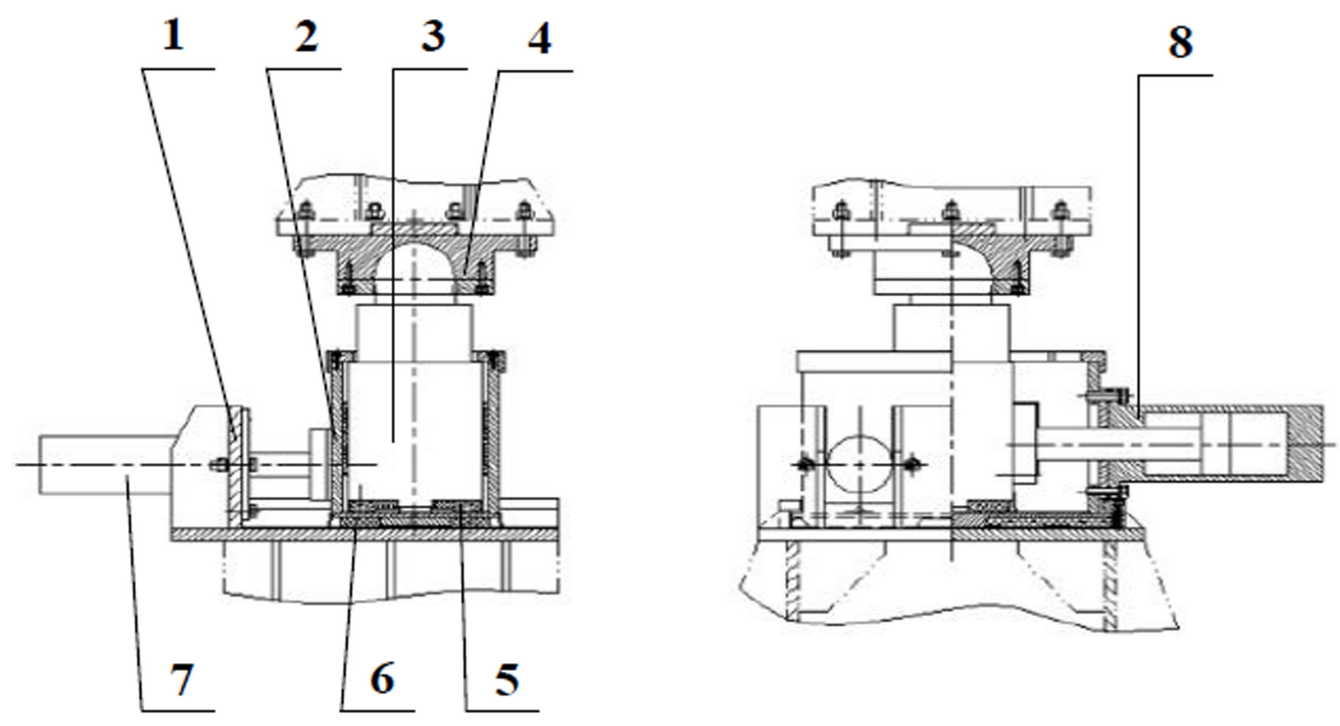

Fig. (7). Assembly drawing of tri-direction jack.

Usually, the base of the equipment is fixed on the horizontal plane. A group of horizontal longitudinal cylinder is installed on the base. Rod flange is fastened with slip case. Slip blocks on the bottom of the slip case and the top surface of the bottom constitute translineing. Except the base and the horizontal longitudinal cylinder, other structure can move 
along horizontal longitudinal direction under the effect of horizontal longitudinal cylinder via this translineing. Horizontal transverse cylinder is installed on the slip case. The piston rod flange is fastened to the vertical cylinder wall. The sliding block on the bottom of the vertical cylinder and the bottom of the slip case constitute a pair of translineing. Under the effect of the horizontal transverse cylinder, the vertical cylinder and the structure above are enabled to move along horizontal transverse direction via this pair of translineing. The vertical cylinder enables the perpendicular displacement, the top of which is linked with ball joint. A connecting plate is designed to correspond to the adjusted cross beam. If it were to be used otherwise, the connecting plate would be redesigned according to specific requirements.

The vertical cylinder, horizontal transverse and horizontal longitudinal cylinder of tri-direction jack range within $200 \mathrm{~mm}$, enabling this system to adapt a larger adjustment range. Therefore, the difficult of boat crane operator in the lifting is lowered. After the cross beam is wholly dropped, it needs to be adjusted both coarsely and precisely via threedirection jack. The magnetostrictive sensor installed in the cylinder can realize the highly accurate closed loop control.

\subsection{Study on Translineing}

The Project is located in the mid Yangtze River, the sand content of the water is larger. It is necessary to carry out research on translineing under the condition of turbid water. In the adjusting system of tri-direction jack, the translineing of stainless steel plate of MGE plate and mirror is applied. Previous engineering experience demonstrates that MGE plate has the characteristic of wearableness, low friction coefficient, low moving and static friction coefficient and large capacity. It can eliminate the negative impact brought about due to uneven track. The material's properties of the MGE block are shown in Table 1:

Table 1. The material's properties of the MGE block.

\begin{tabular}{|c|c|c|c|}
\hline $\begin{array}{c}\text { Tensile strength } \\
(\mathrm{MPa})\end{array}$ & $\begin{array}{c}\text { Compressive strength } \\
(\mathrm{MPa})\end{array}$ & $\begin{array}{c}\text { Density } \\
(\mathrm{g} / \mathrm{cm} 3)\end{array}$ & $\begin{array}{c}\text { Linear expansion coefficient } \\
(\mathbf{l} / \mathbf{o C})\end{array}$ \\
\hline$\geq 30$ & $\geq 65$ & $1.0 \sim 1.1$ & $8.0 \sim 9.1 \times 10-5$ \\
\hline
\end{tabular}

In the construction of displacement adjustment of cross beam, a single group of displacement adjustment cylinder has to overcome the friction $F$ when working:

$$
F=F_{f}+F_{e}
$$

where $F_{f}$ is the sliding friction needed to be overcome, and $\mathrm{F}_{\mathrm{e}}$ is environmental payload, which should be considered in the underwater environment, in which the stream of water has the payload on the adjusted object.

In the normal environment, the wind payload should be considered. The environmental payload can be estimated by national standard and design, while the sliding friction is dependent on the gravity that the adjusted object imposed on the equipment and the sliding friction of translineing. For the certain objects and devices arrangement, the gravity of each equipment can be easily determined. But the sliding friction coefficient of translineing is related to the material and working environment, which should be determined by experiment.

In order to determine the friction coefficient of the MGE mirror stainless steel plate in the different underwater environment, we carry out the corresponding experiment. The experimental set-up is shown in Fig. (8).

Longitudinal load cylinder is used to simulate the payload, and the transverse trust cylinder pushes the sliding case to slide. Meanwhile, the top and bottom sliding material is MGE plate, and top and bottom surface of the sliding material is stainless steel plate. A group of sliding plate and sliding surface constitutes a pair of translineing. In this experiment, there are totally two pairs of sliding sides.

\section{DESIGN OF CONTROL SYSTEM}

\subsection{Control System}

The hanger in the real situation is not the ideal rigid body. Therefore, during the process of displacement adjustment, apart from ensuring the accuracy of final location, the displacement of cylinder of each group of threedirection jacks should be guaranteed according to the requirement to avoid the extra deformation brought about by mis- 
synchronization of the four points of the hanger. Thus, a closed-loop control system should be constructed.

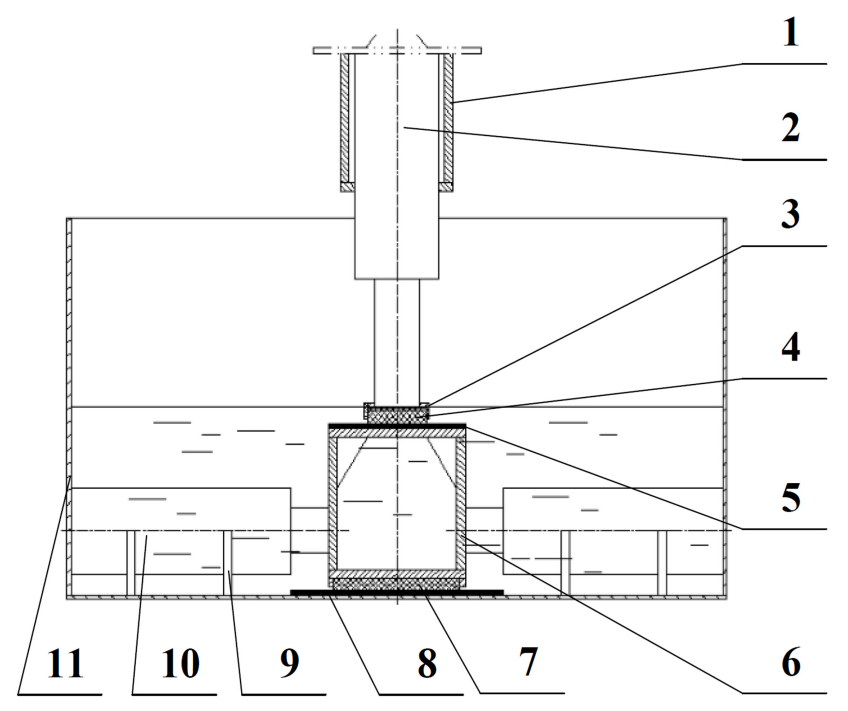

Fig. (8). Experimental set-up.

During the construction of cross beam, three direction jacks are located in the ten meter depth underwater while the hydraulic pump and host computer are above the water on the command ship. Meanwhile, the distance between each base is about seven and eight meters. Therefore, the networking control is applied to ensure the synchronization of each equipment and correct displacement adjustment.

Based on CAN bus, cross beams automatic displacement adjustment control system constitutes real-time networking control system. The control system consists of major control cabin, pump control system, and magnetostrictive sensor, as shown in Fig. (9).

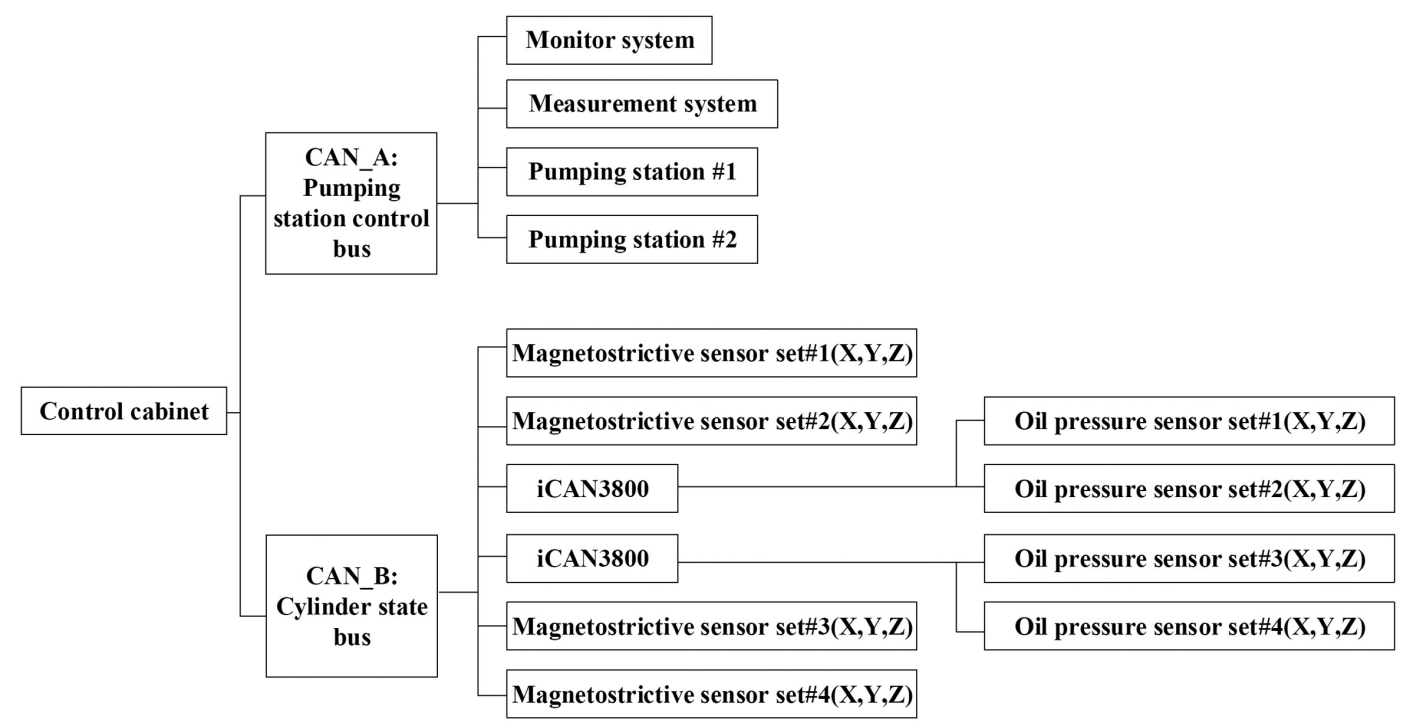

Fig. (9). Structure of control system.

The major control cabin is the core of the electronic control system, communicating with pump control system via CAN_A port. It is used to transmit control data, and at the same time, CAN_A port is communicating with monitor system and measurement system, used to receive monitor data and measurement data. The control cabin communicates with magnetostrictive sensor and iCAN3800 via CAN_B port, receiving hydraulic cylinder data and hydraulic pressure data. 
As the driving unit, the pump control system controls the magnetostrictive sensor in order to control the hydraulic cylinder based on the control data. The magnetostrictive sensor is used to measure the cylinder stroke, transmitting the stroke data to the major control cabin via CAN port. iCAN3800 is used to gain hydraulic pressure data and transmit the data to the major control cabin via CAN port. The control system is shown in Fig. (10).

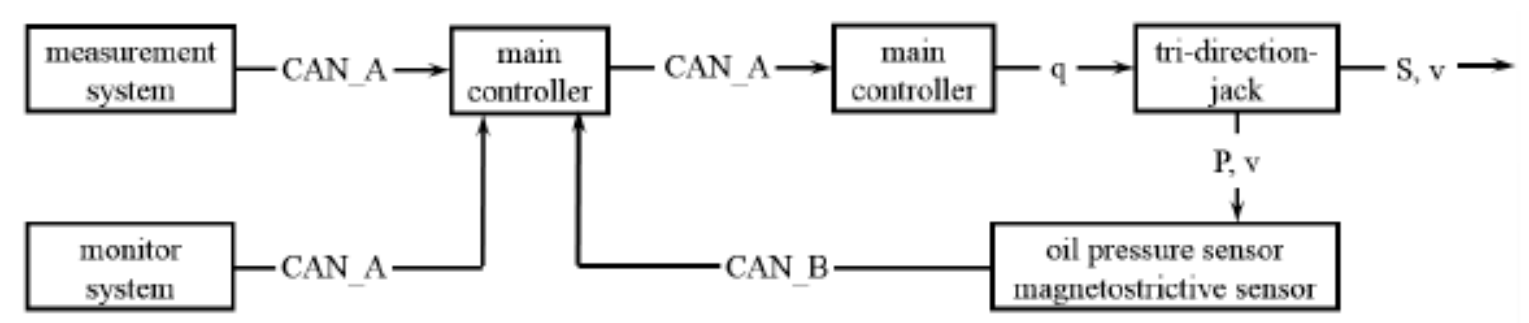

Fig. (10). Block diagram of control system.

\subsection{Control Scheme}

In order to ensure the accuracy of lifting and installation of cross beam, three parts are required to participate in the process of displacement adjustment. The transmission structure is shown in Fig. (11).

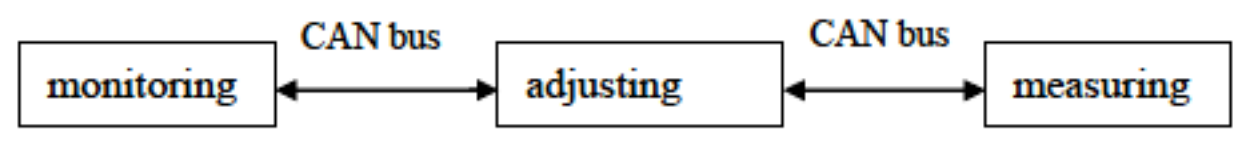

Fig. (11). Structure of information transfer.

The monitoring part sends the objective parameters and coordinates of cross beams which are to be installed to adjusting part to initiate the installation process. Adjusting part sends commands to measuring part, who sends the feedback to adjusting part. The adjusting part carry out the corresponding adjustment according to the message, after which, the measurement is initiated again. The process of measurement and adjustment is performed over and over again until the value measured matches with the target value. After installation of the cross beam is finished, the adjusting part sends the final measuring value to the monitoring part and document it.

\section{APPLICATION OF THE AUTOMATIC DISPLACEMENT ADJUSTMENT OF CROSS BEAM}

To guarantee the accuracy of the position measurement and the precision of final adjustment in the construction, a subsequent order of procedure is usually performed to complete the pointed swinging, rolling, pitching, after which the measuring equipment is able to measure the deviation of the current position of cross beam from the target position. Finally, we perform lifting, shifting and advancing the three kinds of transverse adjustment.

In reality, the deviation measured by equipment between the target position and current position of cross beam is sent via CAN bus to the center controller. The center controller closed loop control the displacement of the cylinder based on the information of magnetostrictive sensor that is installed in the internal cylinder. The whole process can be realized automatically.

Of course, it can be controlled step by step. That is after one time of adjustment, we measure the accuracy of adjustment against the requirement; if not, we initiate the manual adjustment again. The measuring equipment keep constant information exchange with center controller via CAN bus.

The Fig. (12) shows the unilateral ruler installed at the joint part of the cross beam before the adjustment. The ruler scale is 10 millimeter. According to the figure, the alignment of the ruler scale figures out that the side dislocation and top side dislocation of cross beam is over $20 \mathrm{~mm}$ before displacement adjustment. 


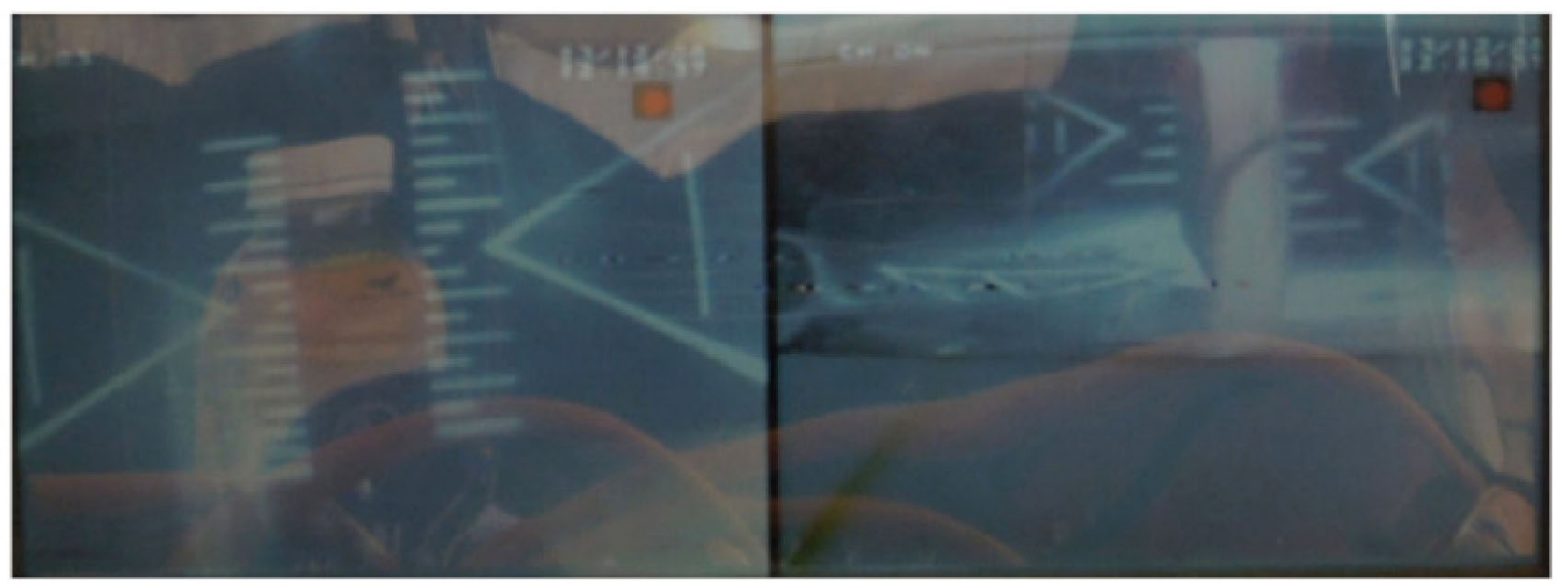

Fig. (12). Photo of alignment staff before positioning

Fig. (13) shows the situation of alignment of ruler after adjustment is completed. The ruler of neighboring cross beams is aligned. After the image processing of computer, the side dislocation and top side dislocation is within 1millimeter.

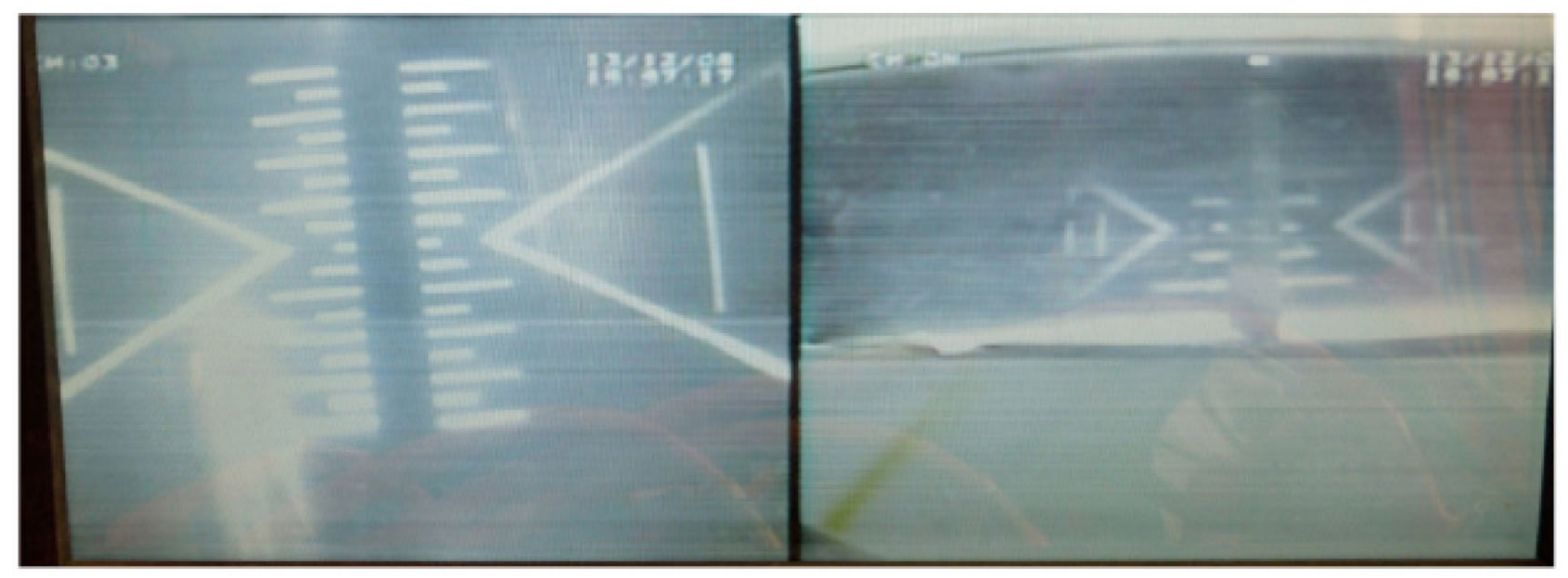

Fig. (13). Photo of alignment staff after positioning.

According to the on the scene construction, the application of three direction jacks and hydraulic synchronous lifting technique, as well as computer networking, is able to complete the displacement adjustment of cross beam within high accuracy. Meanwhile, this set of equipment is independent from hanger, cross beam and other auxiliary, it's easy to install and unload them. Steel lattice columns or guide rod or other temporary structures are unnecessary. Therefore, it is highly efficient automatic displacement adjustment. More often than not, we only have to revise control parameters to apply other similar large scale beam adjustment.

\section{CONCLUSION}

The difficulty of realizing the automation of installation and displacement adjustment of sliding cross beam leads to a long duration of construction. This paper proposes a three direction jack, taking advantage of hydraulic cylinder and MGE sliding block to realize the displacement in the three-dimension space. The structure is compact and easy. Meanwhile, combined with hydraulic synchronous lifting technique, the real time networking control system is established via CAN bus. Thus, the closed-loop control is realized to installation of sliding cross beam quickly, accurately and automatically.

The scene construction demonstrates three direction jack can guarantee the high accuracy of the installation of cross beam. Meanwhile, this set of equipment is independent from hanger, cross beam and other auxiliary. Therefore it is a 
kind of highly efficient adjustment scheme. The equipment can be applied to other similar large scale beam adjustment.

\section{CONFLICT OF INTEREST}

The authors confirm that this article content has no conflict of interest.

\section{ACKNOWLEDGEMENTS}

Declared none.

\section{REFERENCES}

[1] Y. Bian, J. Jiang, Z. Jing, B. Han, A. Li, and G. Liu, "Design and application of hydraulic-walking incremental launching equipment", Open Constr. Build. Technol. J., vol. 7, pp. 1-7, 2013.

[http://dx.doi.org/10.2174/1874836801307010001]

[2] Y. Bian, A. Li, X. Jin, and Q. Zhang, "Coupling analysis method for a large-scale structure exposed to synchronous hoisting loads", Virtual Phys. Prototyp., vol. 4, no. 3, pp. 131-141, 2009.

[http://dx.doi.org/10.1080/17452750903165048]

[3] A. Li, Q. Lan, D. Dong, Z. Liu, Z. Li, and Y. Bian, "Integrated design and process analysis of a blow molding turbo-charged pipe", Int. J. Adv. Manuf. Technol., vol. 73, pp. 63-72, 2014. [http://dx.doi.org/10.1007/s00170-014-5785-8]

[4] M. Marzouk, H.Z. El-Dein, and M. El-Saidc, "Application of computer simulation to construction of incremental launching bridges", J. Civil Eng. and Manag., vol. 13, no. 1, pp. 27-36, 2007.

[5] G. Liu, G. Tan, G. Li, and Y. Rong, "Multidisciplinary design optimization of a milling cutter for high speed milling of stainless steel", Int. J. Adv. Manuf. Technol., vol. 68, pp. 2431-2438, 2013. [http://dx.doi.org/10.1007/s00170-013-4869-1]

[6] R. Marco, "Self-launching erection machines for precast concrete bridges", PCI J., vol. 55, no. 1, pp. 36-57, 2010. [http://dx.doi.org/10.15554/pcij.01012010.36.57]

Received: May 26, 2015 Revised: September 25, 2015 Accepted: September 28, 2015

(C) Zhang et al; Licensee Bentham Open

This is an open access article licensed under the terms of the Creative Commons Attribution-Non-Commercial 4.0 International Public License (CC BY-NC 4.0) (https://creativecommons.org/licenses/by-nc/4.0/legalcode), which permits unrestricted, non-commercial use, distribution and reproduction in any medium, provided the work is properly cited. 